\title{
Numerical Simulation of Root Splitting in Tuff Stone Monument
}

\author{
Liang Ye ${ }^{1}$, Yang Jin ${ }^{1}$, Pingping Sun ${ }^{2, *}$, Yang Liu ${ }^{1}$, Liquan $W^{1}{ }^{1}$ and Qiannan Wang ${ }^{1}$ \\ ${ }^{1}$ School of Civil Engineering and Architecture, Zhejiang University of Science and Technology, Hangzhou 310023, China \\ ${ }^{2}$ College of Civil Engineering and Architecture, Zhejiang University of Water Resources and Electric Power, Hangzhou 310018, China
}

Received 27 February 2021; Accepted 11 June 2021

\begin{abstract}
The root splitting of tuff stone monument is one of the main reasons for the regional destruction of stone monument in Zhejiang province, China, which is also a new research difficulty in the destruction of stone monument. On the basis of analyzing the root splitting mechanism of stone monument, the mechanical model of the root splitting process of tuff stone monument was summarized and established, and the equation of the root splitting expansion force was solved by means of elastic mechanics and fracture mechanics. The equivalent thermal expansion method was used to simulate the growth and expansion of root system, and the extended finite element method (XFEM) was used to calculate the crack expansion law of stone monument. Results show that the root splitting expansion force is affected by root growth expansion factor, mechanical strength of plant root and rock mass, and fracture morphology. The numerical solutions of the root splitting expansion force and tensile stress obtained by the equivalent expansion method are in good agreement with the analytical solutions. The crack propagation of rock mass in the root splitting is closely related to the crack morphology and root growth. The law of crack propagation is consistent with the actual failure characteristics of stone monument. The research method in this study can provide the theoretical basis for the damage of similar stone monument.
\end{abstract}

Keywords: Tuff, Stone monument, Mechanical model, Root splitting, Numerical simulation

\section{Introduction}

At present, stone monument such as cave temples and cliff carvings in China are all located in scenic spots, the management departments generally pay attention to the landscape ecological environment, especially in the southern region where vegetation is developed and has a high coverage rate. In the process of protecting stone monument such as Feilaifeng stone statues and Shaoxing Keyan rock statues, many damage diseases caused by plant root have been found [1-3]. However, due to the lack of related research, there is no corresponding quantitative model analysis on the degree and progress of damage in stone monument caused byplant root . Finally, only a fuzzy balance can be made. Follow-up monitoring shows that some plant roots are still showing a continuous impact on the statues.

There are a large number of tuff stone monuments with a long history in Zhejiang province, China. These tuff stone monuments have experienced natural weathering and different degrees of man-made damage in the long history, and are suffering from different degrees of surface deterioration, corrosion and even destruction. However, a large number of grotto stone relics are attached to the steep rock slope, and the mechanical action of plant roots in the rock mass produces a large number of cracks, and the rock mass is gradually destroyed, weathered and disintegrated for a long time. Therefore, if appropriate and effective protection measures are not taken, these cultural heritages that witness the pace of history will disappear forever in the near future, and irreparable losses will also be caused.

*E-mail address: sunpp@ziweu.edu.cn

ISSN: 1791-2377 @ 2021 School of Science, IHU. All rights reserved.

doi:10.25103/jestr.143.16
The root splitting of stone monument brought by higher plants is a gradual and lengthy process, and the destruction process can be summarized into three stages [4]: First, the short plant roots grow normally in the cracks of stone monument. Second, its growth and radial coarsening roots are constrained by the crack wall, which leads to compressive damage to the rock body and surrounding rock mass, causing crack widening. Third, the roots growth tends to widen the cracks or structural weaknesses, resulting in further damage to stone monument. The study on the mechanism of root splitting of stone monument belongs to a new and urgent field. The establishment of the mechanical relationship between plant roots and stone monument can provide a theoretical basis for the detection and evaluation of tuff stone monument and the establishment of prevention and control measures, which is of great historical and practical significance for the protection of stone monument.

\section{State of the art}

At present, the research on root splitting is only at the conceptual level. Based on a large number of investigations and field collection of spruce roots, Malik et al. pointed out that the growth of roots would fill the space within rock fractures, and the root morphology would become irregular according to the shape change of fractures [5]. Pawlik et al. studied the growth morphology of spruce root in rock mass cracks and loose soil based on the root anatomy. The results showed that the growth morphology of root was mainly oval, and the ratio of long and short axes of root growing in rock mass cracks was greater than that in loose soil [6]. Liu et al. carried out an on-site investigation on the Epang Palace site in Xi'an, and discussed the relationship between plant roots, 
root length, root diameter, plant species and the crack area of the soil site [7]. Zhang et al. investigated the material composition, basic mechanical properties and rock mass structure characteristics of Feilaifeng rock mass, and found that root splitting was the main reason for the widening of the fracture in the rock mass [8].

Limited by the lack of systematic research methods and means on plant root growth, current research on plant roots growth model mainly relies on field monitoring and indoor cultivation experiments. Liu et al. used the trunk radial change recorder to continuously record the change process of radial growth of different differentiated red vertebral bodies, synchronously monitor meteorological and environmental factors, and established the correlation between radial growth of trunk and various factors [9]. Calusi et al. proposed a mathematical model of root growth based on root-soil interaction, and the rationality of the model was verified by comparing the data collected in indoor cultivation experiments and real environment [10]. Kolb et al. studied the radial force generated by the root system under the change of crack width and its influence on the growth of the root system through photoelastic experiments. The results showed that the outer epidermis of the root system was compressed under the constraint of crack wall, but the middle part was not affected. Meanwhile, the radial force of the root system increased with the increase of time [11].

Research on root splitting damage of stone monument is also limited and insufficient. Su et al. studied the formation mechanism of dangerous rock mass in Bailiandong site, and found that root splitting would make the original joint and fissure continuously open and expand, which would intensify the deformation and failure of rock mass [12]. Fulvio and Claudio proposed a micromechanical model for tuff stone masonry by assuming a periodic composite with two components, namely tuff stones and mortar. The accuracy and robustness of the micromechanical model were assessed by simulating nonlinear response and crack patterns of masonry in different geometrical, boundary and loading conditions related to axial and diagonal compression tests [13]. Anthony presented a finite element model for the prediction of discrete fracture propagation in rock structures loaded in compression. The predictions of the model are compared with the observed fracture response of a real rock structure. Results show that the model accurately predicts both stable and unstable fracture progagations observed experimentally [14]. Based on the maximum tensile stress and The Mohr-Coulomb criterion, Yun et al. improved the fracturing modeling algorithm in the numerical manifold method (NMM) and applied it to the comprehensive simulation study of rock fracture of rock samples with preexisting fractures. The simulation results of fracture propagation and the final fracture development path were in good agreement with the experimental results [15]. Kuksenko and Tomilin propose a two-stage model of rock fracture. The advantage offered by this model is that a notion of the rank of fracture (fracture size) is introduced, and criteria are presented for both fracture nucleation and the transition of the failure process from one scale to another [16].

Since the corresponding quantitative analysis of crack propagation process of stone monument by root splitting has not been carried out [17-21]. This study adopted theoretical analysis and numerical simulation to study root splitting in tuff stone monument. The root splitting action of stone monument was reasonably simplified and assumed combining elastic mechanics theory and fracture mechanics method. The mechanics model of root splitting of stone monument was established and the solving equation of root splitting expansion force was deduced. Secondly, the equivalent thermal expansion method was used to simulate the root growth and expansion. Finally, the extended finite element method (XFEM) was used to simulate the fracture propagation of tuff stone monument rock mass. The results of this study provide a reference for exploring the mechanical mechanism of root splitting of stone monument.

The rest of the study is organized as follows. Section 3 describes two research methods and basic assumptions. The analysis and discussion of the results are given in Section 4, and the conclusion is summarized in Section 5.

\section{Methodology}

\subsection{Basic hypotheses}

Most of the stone monument rock mass have highly developed joints and cracks, etc. From the perspective of fracture mechanics, the root splitting expansion force can drive the pre-existing cracks of rock mass to produce type (I) expansion [22]. In order to explore the mechanical mechanism of the root splitting expansion force on the fracture expansion of stone monument rock mass, the following assumptions are made:

(1) For the convenience of research, it is assumed that the fractures are approximately simplified to the ellipsoid of transverse section, and the plant roots are approximately flat ellipsoid. The longitudinal length of fractures and plant root is much larger than the transverse radius, and the problem can be regarded as the plane strain state, as shown in Fig. 1.

(2) The stone monument rock mass and the plant roots are homogeneous and isotropic elastic medium, and the plant roots in the cracks are incompressible.

(3) The root splitting expansion force is distributed uniformly along the crack wall without considering the friction between the root system and the crack wall.

(4) During the growth and expansion of plant root, the "complete contact" state is maintained between the stone monument rock mass and plant root, that is, the normal stress and normal displacement of the crack surface are equal, which always satisfies the deformation coordination condition.

\subsection{Analysis method of mechanical mechanism of stone relic root splitting}

In the process of growth, the plant root grows and expands freely without surrounding constraints, and their volume expansion is as follows:

$$
\Delta V_{p}=\alpha V_{0 p}
$$

where, $V_{0 p}$ is the initial volume of plant root; $\alpha$ is the equivalent growth expansion factor of plant root, and different represents the volume expansion changes in the growth process of plant root. 

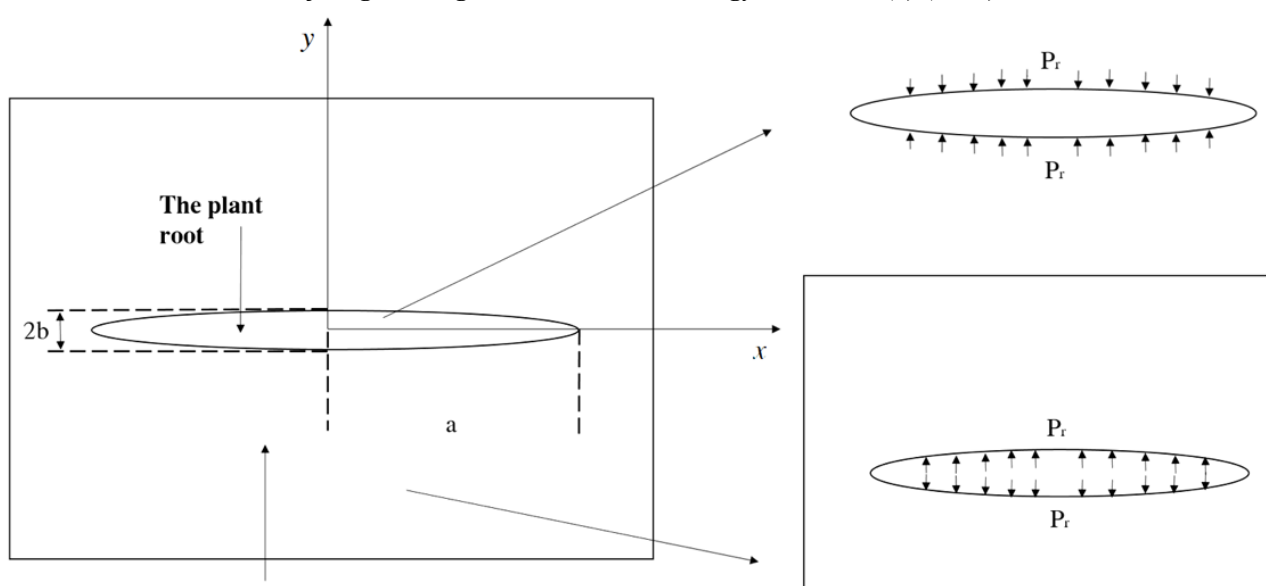

The stone monument rock mass

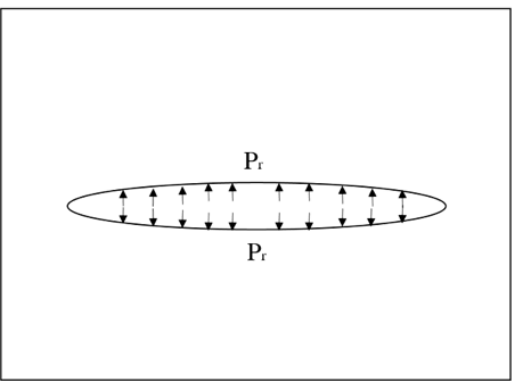

Fig. 1. Diagram of root splitting.

Since it is simplified to plane strain problem, the initial volume of plant root can be expressed as:

$$
V_{0 p}=\pi a b
$$

In the process of plant root growth, it is constrained by the crack wall, which will produce the corresponding root splitting expansion force $P_{\mathrm{r}}$, this expansion force acts on plant root uniformly and acts as a constraint, which causes compressive deformation relative to the unconstrained state. According to the plane strain problem of elasticity, the volumetric strain of plant root is:

$\varepsilon_{v}=\frac{3\left(1-2 \mu_{p}\right)}{E_{p}} P_{\mathrm{r}}$

where, $\mu_{p}, E_{p}$ are Poisson's ratio and elastic modulus of plant root, respectively.

Then, the actual expansion volume of plant root under the constraint of root splitting expansion force is:

$$
\begin{aligned}
& V_{p}=\left(V_{0 p}+\Delta V_{p}\right)\left(1-\varepsilon_{v}\right) \\
& =\pi a b(1+\alpha)\left[1-\frac{3\left(1-2 \mu_{p}\right)}{E_{p}} P_{\mathrm{r}}\right]
\end{aligned}
$$

Regardless of the physical force, the elliptic crack is affected by the root splitting expansion force. According to the elastic mechanics combined with the complex variable function, the long and short axial boundary displacement of the crack can be calculated as [23]:

$$
\begin{aligned}
& u_{a}=\frac{P_{r}^{\prime} R}{2 G_{s}}\left(1-\frac{3-\mu_{s}}{1+\mu_{s}} m\right) \\
& u_{b}=\frac{P_{r}^{\prime} R}{2 G_{s}}\left(1+\frac{3-\mu_{s}}{1+\mu_{s}} m\right)
\end{aligned}
$$

where, $G_{s}=\frac{E_{s}}{2\left(1+\mu_{s}\right)}, R=\frac{a+b}{2}, m=\frac{a-b}{a+b} \mu_{S}, E_{s}$ are the

Poisson's ratio and Shear modulus of the stone monument rock mass, respectively. Where, if $a \gg b$ the width of the crack is ignored, then $R=\frac{a}{2}, m=1$.

Therefore, the change of crack at the center of the long axis can be simplified as:

$$
\begin{aligned}
& \Delta a=\mu_{a}=-\frac{P_{r}}{2 G_{s}} \frac{a\left(1-\mu_{s}\right)}{1+\mu_{s}} \\
& \Delta b=\mu_{b}=\frac{P_{r}}{G_{s}} \frac{a}{1+\mu_{s}} \\
& \text { If } a \gg b,|\Delta a|=\frac{|\Delta b|\left(1-\mu_{s}\right)}{2} \text { for small quantity. }
\end{aligned}
$$

Therefore, it can be approximated that $|\Delta a| \times|\Delta b| \approx 0$

Then, the expansion volume of the fracture is:

$$
\begin{aligned}
& V_{s}=\pi(a b+a \Delta b+b \Delta a) \\
& =\pi a\left(b+\frac{P_{r}}{G_{s}} \frac{a}{1+\mu_{s}}-\frac{P_{r}}{2 G_{s}} \frac{b\left(1-\mu_{s}\right)}{1+\mu_{s}}\right)
\end{aligned}
$$

Combining Eqs. (4) and (9), the solution of root splitting expansion force of stone monument can be expressed as:

$$
P_{r}=\frac{\alpha}{\frac{2 \theta-1+\mu_{s}}{E_{s}}+\frac{3(1+\alpha)\left(1-2 \mu_{p}\right)}{E_{p}}}
$$

where, $\theta=\frac{a}{b}$.

\subsection{Numerical analysis for root splitting}

\subsubsection{Simulation of plant root growth and expansion} Without considering the environmental adaptability of plant root, it is assumed that the development and growth of plant root show radial uniform growth. ABAQUS software was used to simulate the growth and expansion of plant root. Other assumptions were the same as the basic hypotheses. The method of equivalent thermal expansion was adopted to realize the change of growth volume expansion of plant root 
by changing temperature, and the growth and expansion factor of plant root could be controlled by changing thermal expansion coefficient. Its volume expansion can be expressed as:

$$
\Delta V=\beta \cdot \Delta T \cdot l_{0} \cdot V_{0}
$$

where, $\beta$ is the coefficient of thermal expansion, $\Delta T$ is the change of temperature. Considering the plane strain state, $l_{0}=1$.

The conversion relation between plant root growth expansion factor and thermal expansion coefficient can be obtained from Eqs. (1) and (11):

$$
\alpha=\beta \Delta T
$$

\subsubsection{Calculation of crack propagation}

Based on the equivalent expansion method to simulate root growth and expansion, the XFEM was used to simulate the crack propagation of tuff stone monument rock mass. The XFEM was firstly proposed by Belytschko. Compared with the finite element method, the XFEM does not need to redivide the mesh when analyzing the crack growth problem. Its core idea is to introduce a enrichment function that can reflect cracks on the basis of conventional finite element, and the enrichment function is [24]:

$$
u=\sum_{I=1}^{N} N_{I}(x)\left[u_{I}+H(x) a_{I}+\sum_{\alpha=1}^{4} F_{\alpha}(x) b_{I}^{\alpha}\right]
$$

where, $N_{I}(x)$ is the displacement function of general finite element; $u_{I}$ is the node displacement related to the continuous part of the finite element solution; $a_{I}$ and $b_{I}{ }^{\alpha}$ are the degree of freedom is strengthened for the joints of crack penetration element and crack tip element, respectively; $H(x)$ and $F_{\alpha}(x)$ are the crack tip step function and asymptotic function, respectively.

\subsubsection{Criteria for crack propagation}

In the XFEM, there are various commonly used criteria for judging crack initiation: maximum principal stress criterion, maximum principal strain criterion, maximum normal stress criterion, maximum normal strain criterion, quadratic nominal stress criterion, and quadratic nominal strain criterion [25]. Because the concept of maximum principal stress is clear and the numerical calculation is easy to converge, the maximum principal stress criterion was adopted in this study to simulate the propagation of root split fractures in single fractured rock mass.

Maximum principal stress is a macroscopic index proposed to judge crack growth from the perspective of maximum principal stress, that is, when the maximum principal stress at the crack tip reaches the critical value $\sigma_{t}$, crack initiation and propagation occur along the direction perpendicular to the maximum principal stress. The maximum principal stress was used to study the crack free stage and to judge the crack initiation position of the material, which is expressed as:

$$
f=\left\{\frac{\left\langle\sigma_{\text {max }}\right\rangle}{\sigma_{\text {max }}^{o}}\right\}
$$

where, $\sigma_{\text {max }}^{o}$ is the maximum allowable principal stress, $\sigma_{\max }$ is the calculated maximum principal stress. While $\sigma_{\max }<0,\left\langle\sigma_{\max }\right\rangle=0$; while $\sigma_{\max } \geq 0,\left\langle\sigma_{\max }\right\rangle=\sigma_{\max }$. If $f \geq 1$, the material began to crack.

\subsubsection{Numerical model and selection of parameters}

The model of tuff stone monument rock mass is $50 \mathrm{~mm} \times 50 \mathrm{~mm}$, and the long half axis of plant root is $20 \mathrm{~mm}$ and the short half axis is $4 \mathrm{~mm}$, as shown in Fig. 2. CPE4R was selected as the element type of rock mass and plant root system, and a structured grid was used and subdivided at the crack tip. The lateral and vertical displacements were constrained by the outer boundary of rock mass, and the loading was carried out by changing the temperature change of plant root region, with the initial temperature being $0{ }^{\circ} \mathrm{C}$. The material parameters of the model are referred to references [26-27], and the specific values are shown in Table. 1.

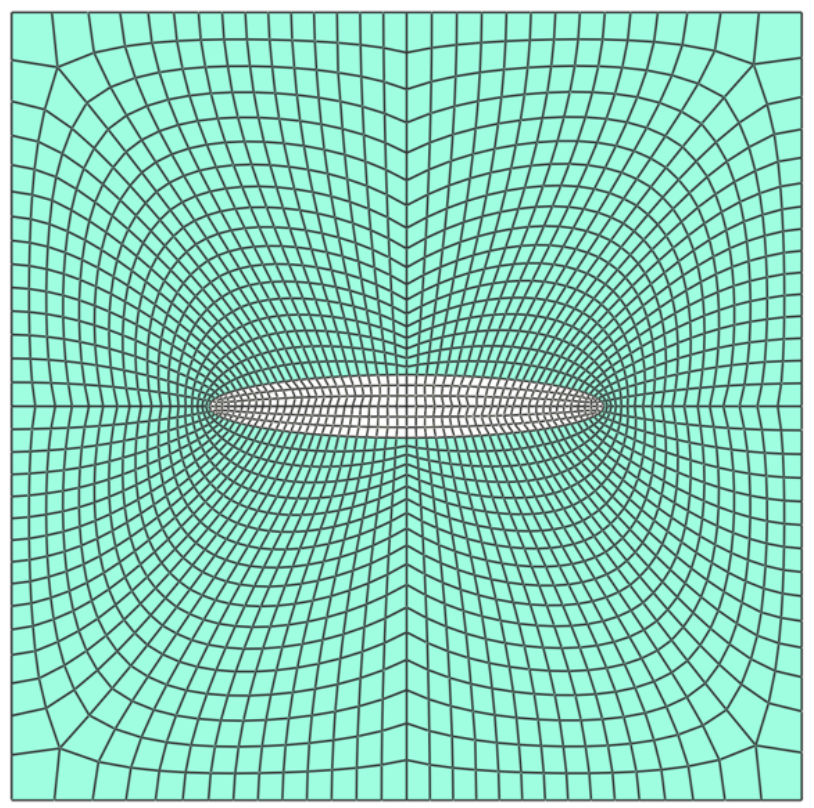

Fig. 2. Numerical model diagram.

Table. 1. Model material parameters

\begin{tabular}{c|c|c}
\hline Parameter & Tuff stone monument & Plant root \\
\hline Elasticity modulus $(\mathrm{GPa})$ & 64.9 & 12.8 \\
Poisson's ratio & 0.33 & 0.38 \\
Thermal expansivity $\left({ }^{\circ} \mathrm{C}^{-1}\right)$ & - & $5.46 \times 10^{-6}$ \\
Tensile Strength $(\mathrm{MPa})$ & 8.4 & - \\
\hline
\end{tabular}

\section{Results and Discussion}

\subsection{Analysis of root splitting expansion force}

According to Eq. (10), the change curve of the root splitting expansion force of stone monument on the expansion growth factor of plant root and the elastic modulus of rock mass is drawn, as shown in Figs. 3 and 4.

When the root growth expansion factor and crack morphology were determined, the root splitting expansion force of rock mass was positively correlated with the elastic modulus of rock mass and plant root. When the elastic modulus of rock mass and plant root reached a certain value, the root splitting expansion force of rock mass increased gradually. 


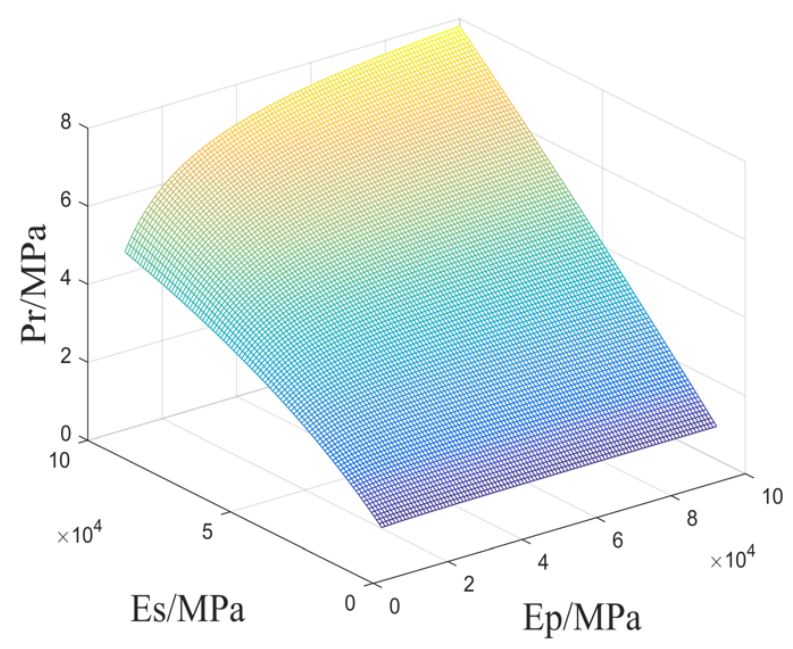

Fig. 3. The relationship amomg the elastic modulus of the rock mass and the plant root system and the root splittig expansion force.

When the elastic moduli of rock mass and plant root are known, the root splitting expansion force has negative correlation relationship with fracture morphology. When the ratio of the length of axis tends to zero, the root splitting expansion force tends to infinity. The higher the major and minor axis is, the smaller root the splitting expansion force is When the ratio of the lengths of axis is higher than a certain value, the root splitting expansion force change interval tends to be stable. However, there is a positive correlation between root splitting expansion force and growth expansion factor of stone monument. The larger the root growth expansion factor is, the greater the root splitting expansion force of stone monument is. It also indicates that the root splitting expansion force of stone monument is very sensitive to the growth of plant root.

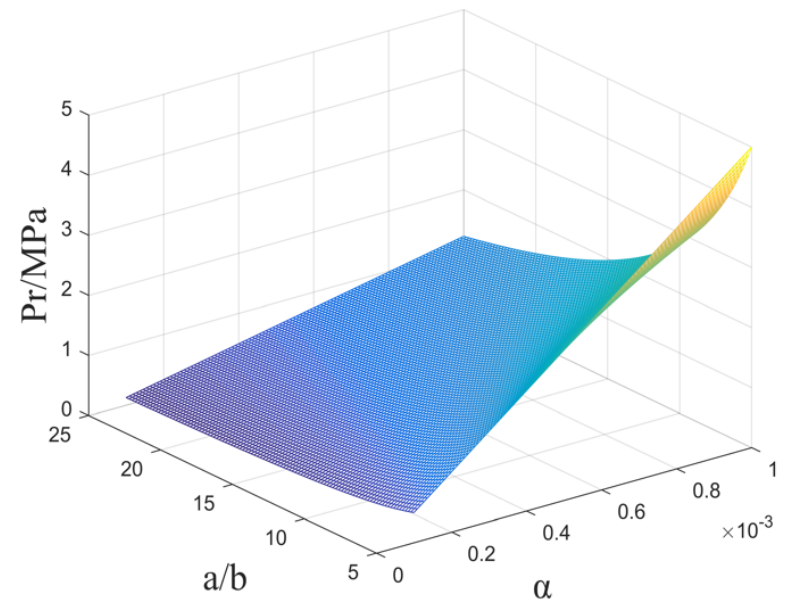

Fig. 4. The relation of root splitting expansion force with root growth expansion factor and fracture morphology.

\subsection{Stress field analysis of crack tip}

The crack expansion of stone relics under the action of root splitting expansion force can be regarded as the fracture problem of open type (I) crack. According to the knowledge of fracture mechanics, the analytical solution of the stress field near the crack tip of the cultural rock mass under the action of root splitting expansion force can be expressed as [23] :

$$
\left.\begin{array}{c}
\sigma_{x x}(r, \theta)=\frac{K_{I}}{\sqrt{2 \pi r}} \cos \frac{\theta}{2}\left(1-\sin \frac{\theta}{2} \sin \frac{3 \theta}{2}\right) \\
\sigma_{y y}(r, \theta)=\frac{K_{I}}{\sqrt{2 \pi r}} \cos \frac{\theta}{2}\left(1+\sin \frac{\theta}{2} \sin \frac{3 \theta}{2}\right) \\
\tau_{x y}(r, \theta)=\frac{K_{I}}{\sqrt{2 \pi r}} \sin \frac{\theta}{2} \cos \frac{\theta}{2} \cos \frac{3 \theta}{2}
\end{array}\right\}
$$

where, $K_{I}$ is the stress intensity factor.

The stress intensity factor of the crack surface under the action of uniformly distributed root splitting expansion force is:

$$
K_{I}=\int_{-a}^{a} \frac{2\left(P_{\mathrm{r}} d x\right) \sqrt{a}}{\sqrt{\pi\left(a^{2}-x^{2}\right)}}=P \sqrt{\pi a}
$$

Matlab was used to draw the stress distribution nebulae of Eq. (15), as shown in Fig. 5.

As seen from Fig. 5, under the action of root splitting expansion force, the fracture tip of stone monument rock mass produces obvious stress concentration, and the closer it is to the fracture tip, the greater the stress is, reaching the order of tens of MPa in numerical value. Visible for dense hard rock, if there is a closed fractures, root growth expands the root of the split expansion force will be very great, in reality, of course, this kind of situation does not exist, however, it is certain that plant roots have a positive promoting effect on the existence of crack propagation in rock mass, and this has potential harm to the stability of stone monument.

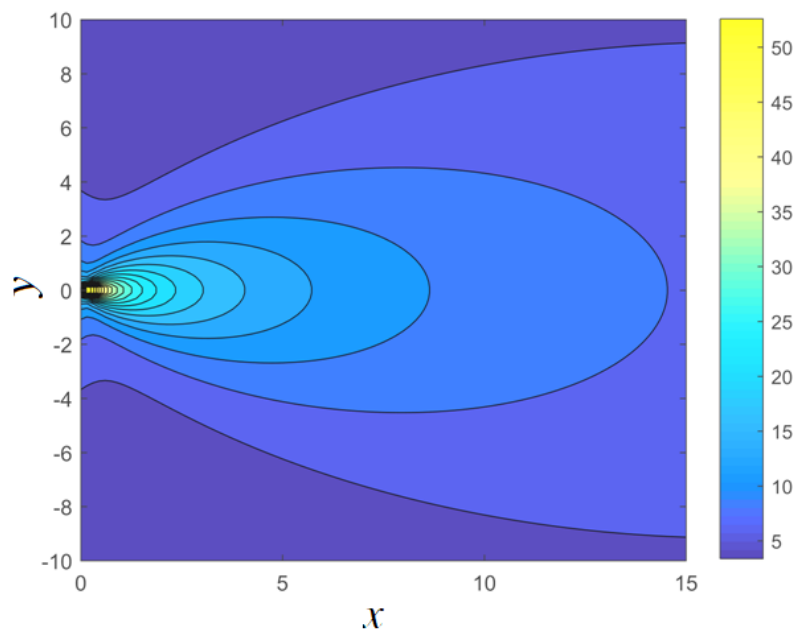

(a) $\sigma_{x}$

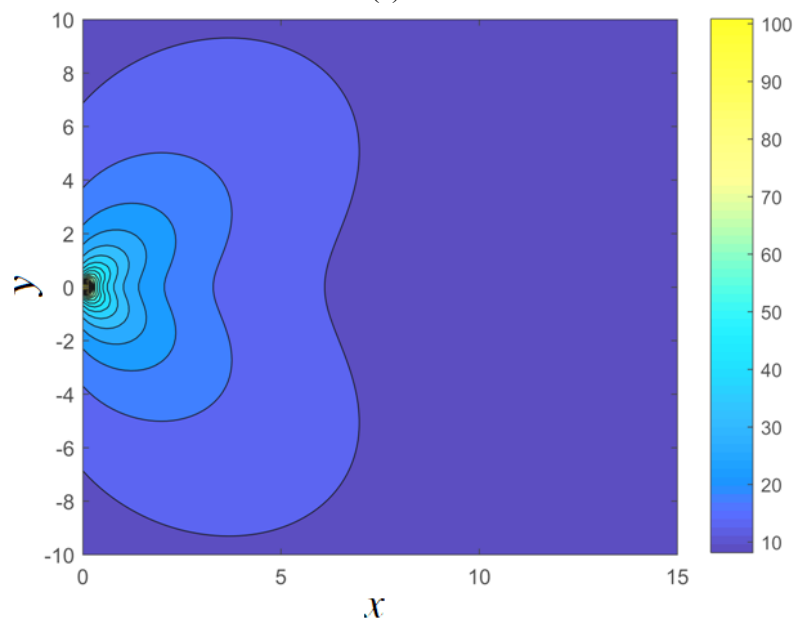


(b) $\sigma_{y}$

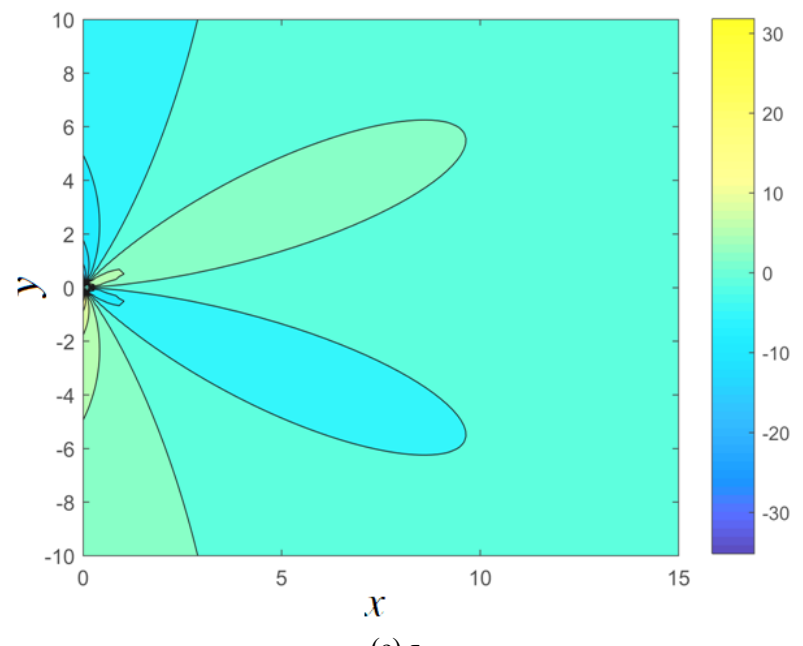

(c) $\tau_{x y}$

Fig. 5. Stress distribution at crack tip of stone monument rock mass.

\subsection{Demonstration of numerical simulation method}

By simulating the growth and expansion factors of different plant root (different temperature differences), the stress distribution cloud map of the fracture tip of the tuff stone monument rock mass was obtained, as shown in Fig 6. As can be seen from Fig. 6, under the effect of the root expansion force, the stress of tuff rock mass is symmetrically distributed about the crack center, and the crack tip generates an obvious stress concentration, and the stress far away from plant roots is significantly reduced. It indicates that the influence of plant roots on the stress of tuff rock mass is only in the area around the fissure, and the influence of plant roots on the stress of tuff rock mass is small beyond a certain range. At the same time, it can be seen that the crack tip at the long axis of the crack is mainly under tension, and the crack wall around the short axis is mainly under compression. Therefore, it can be concluded that the root splitting failure of tuff stone monument is mainly under tension.

Combining Eqs. (10) and (15), the change curve of root splitting expansion force, growth expansion factor and stress change curve of crack tip of stone relics are drawn, as shown in Figs. 7 and 8. It can be seen from Fig. 7, the root splitting expansion force of tuff stone monument rock mass increases linearly with the increase of growth expansion factor, and the numerical solution is in good agreement with the analytical solution, indicating that the equivalent thermal expansion method is in good agreement to simulate the growth and root expansion. According to Fig. 8, under the same calculation parameters, at the crack tip, $\sigma_{y y}(0,0)$ tends to be infinite, and the overall trend of the numerical solution is in good agreement with the analytical solution. At the distance of $r>10 \mathrm{~mm}$ from the crack tip, there is a certain error between the numerical solution and the analytical solution. The main reason is that the shape of rock mass cracks is changed due to root expansion and extrusion during the numerical calculation.

\subsection{Discussion on the law of crack propagation}

\subsubsection{Analysis of deformation of fracture morphology}

Set different fracture morphology $\theta_{1}=\frac{20}{4}, \theta_{2}=\frac{24}{4}$, $\theta_{3}=\frac{28}{4}, \theta_{4}=\frac{32}{4}$, and $\theta_{5}=\frac{36}{4}$. As shown in Fig. 9, the root splitting deformation diagram of the tuff stone monument rock mass is obtained. Fig. 9(a) is the root splitting displacement diagram of the tuff stone monument rock mass in the form of $\theta_{5}=\frac{36}{4}$. As can be seen from Fig. 9(a), under the action of root splitting expansion force, the fracture wall displacement value at the short axis is larger than that at the long axis, and the fracture tip is accompanied by tension cracks extending along the long axis. The relationship curve between the fracture length of rock mass expansion and the axial ratio of the fracture is obtained through analysis, as shown in Fig. 9(b). It can be seen from Fig. 9(b), as the ratio of the long and short axes of fractures increases, the fracture propagation length gradually decreases. The results show that the shorter and wider the preexisting fissure of stone monument rock mass is, the more obvious the damage of root splitting becomes.

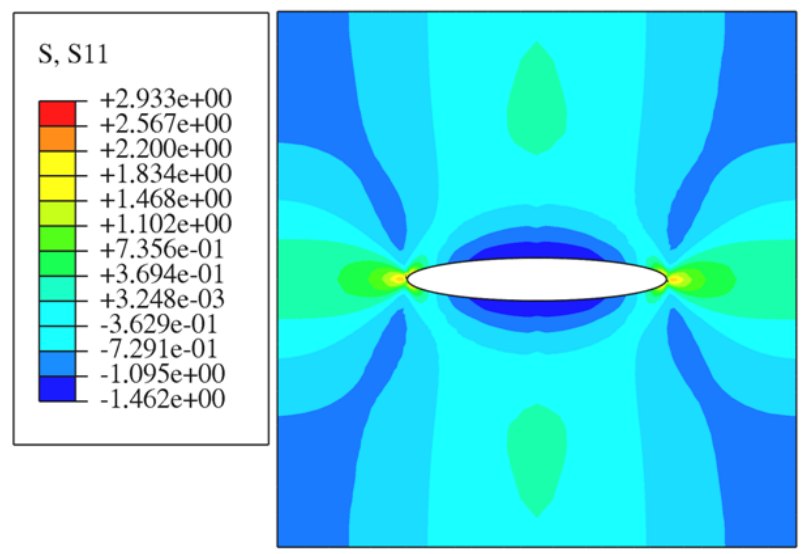

(a) $\sigma_{x}$

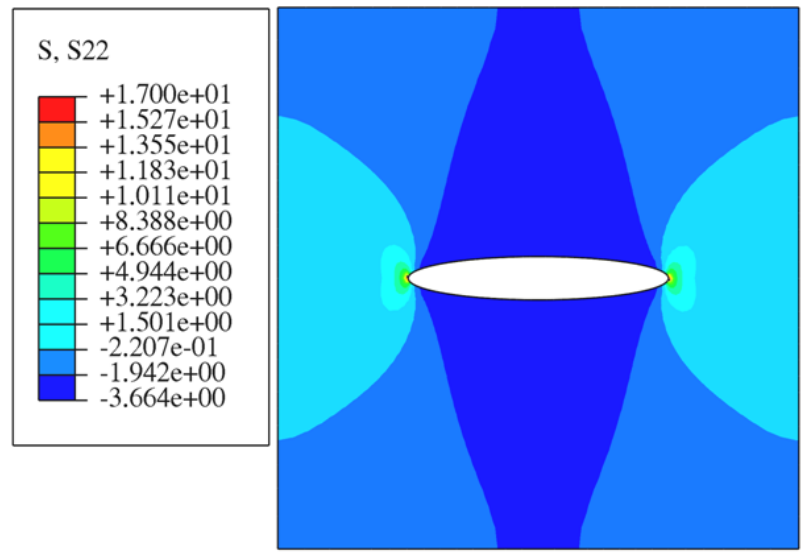

(b) $\sigma_{y}$

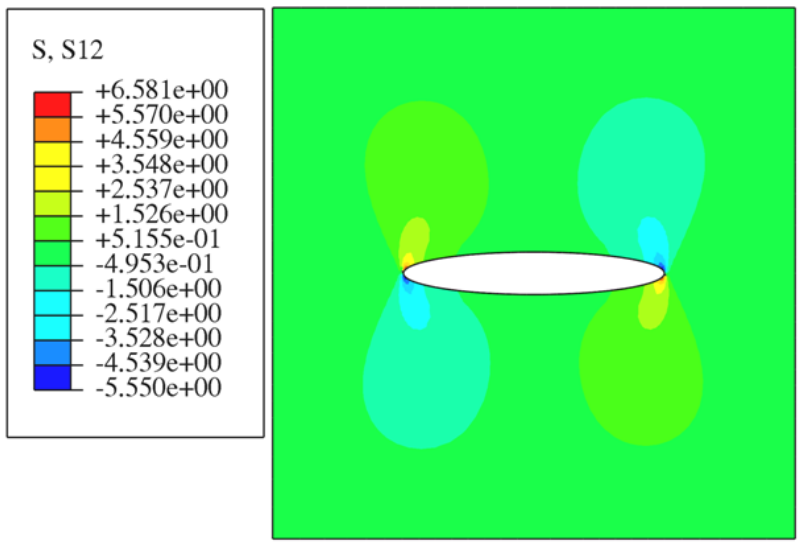

(c) $\tau_{x y}$

Fig. 6. Stress distribution in tuff stone monument rock mass. 
Liang Ye, Yang Jin, Pingping Sun, Yang Liu, Liquan Wu and Qiannan Wang/

Journal of Engineering Science and Technology Review 14 (3) (2021) 140 - 147

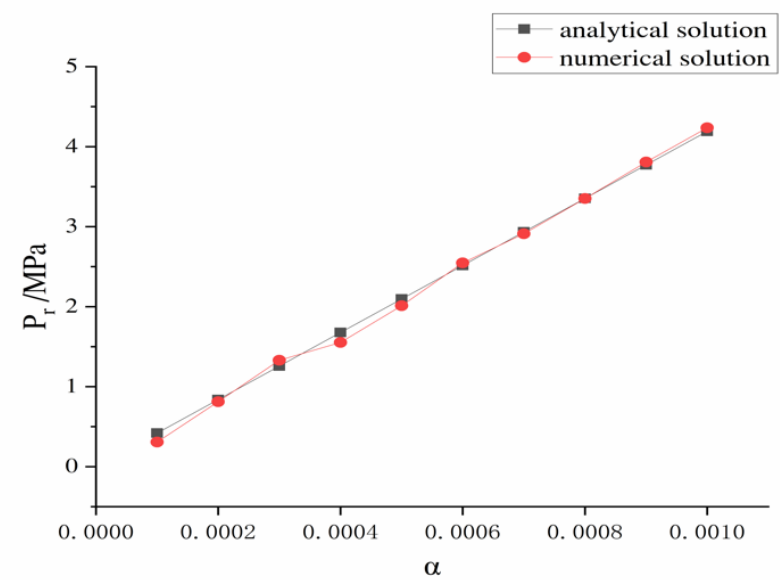

Fig. 7. The variation curve of root splitting expansion force with root growth expansion factor in tuff stone monument rock mass

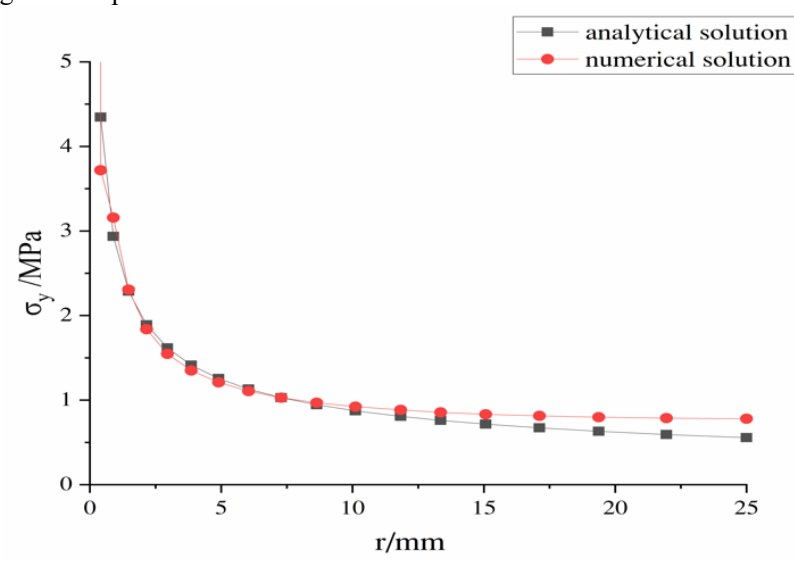

Fig. 8. Curve of tensile stress variation at crack tip of tuff stone monument rock mass

Fig. 10 shows the fracture propagation path diagram of tuff stone cultural rock mass under different root growth expansion factors. As can be seen from Fig. 10, the influences of different root growth expansion factors on the fracture expansion of rock mass are greatly different. When $\alpha=0.001$, the fracture expansion does not occur; when $\alpha=0.003$, the fracture expansion occurs on one side of the long axis; when $\alpha=0.005$, the fracture expansion occurs on both sides of the long axis. This indicates that the root splitting has a time accumulation effect on the crack expansion of stone monument, and the crack expansion develops from unilateral expansion to bilateral expansion as the root volume increases during the growth process. Therefore, without considering the growth activity of plant root, the more rapidly the roots grow and expand, the more obvious the damage to stone monument is.

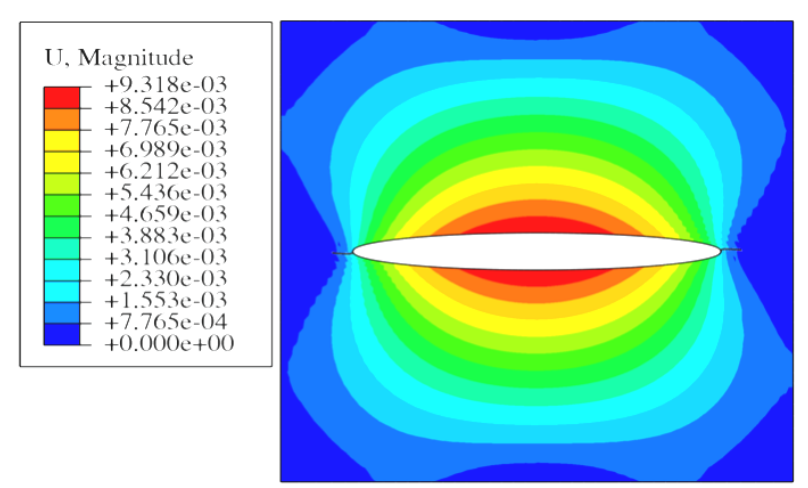

(a) Root splitting displacement of stone monument rock mass

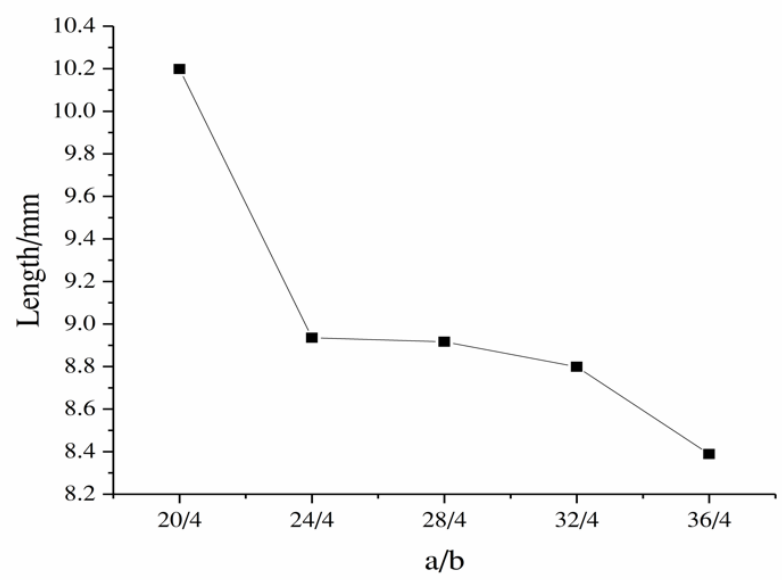

(b) The length of the extended fissure with the axial ratio

Fig. 9. Root splitting deformation of tuff stone monument rock mass.

\subsubsection{Expansion path of root growth expansion factor}

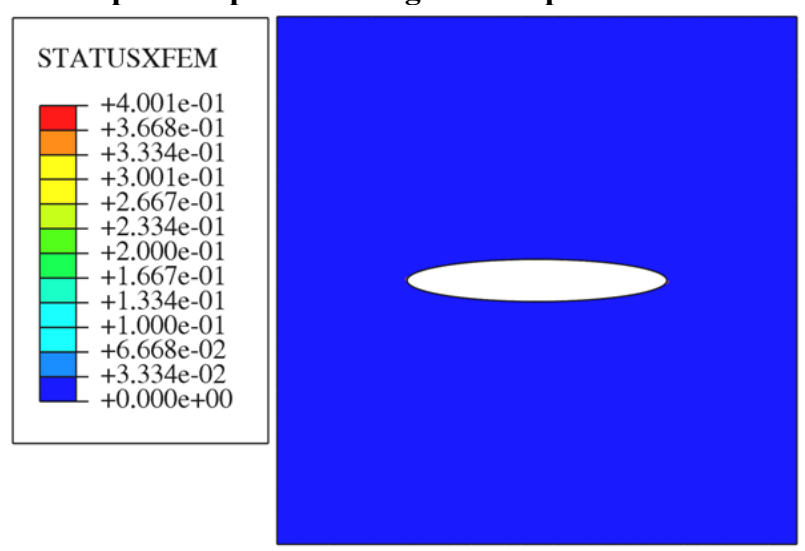

(a) $a=0.001$

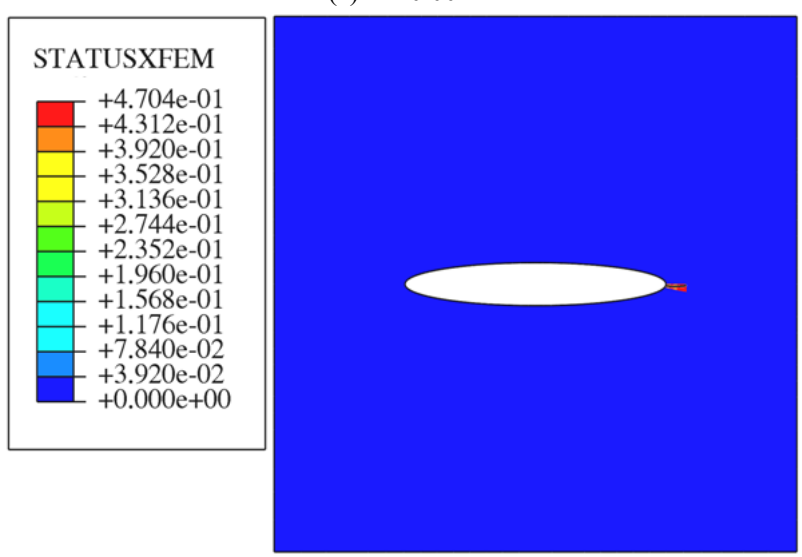

(b) $a=0.003$

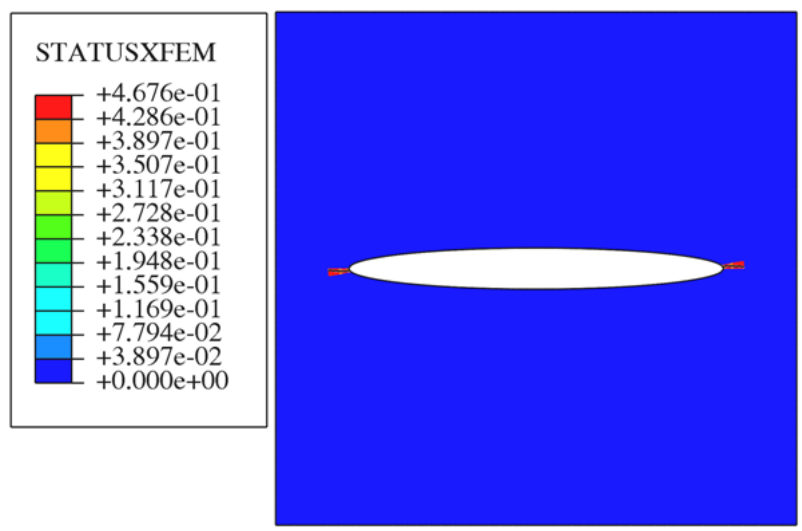

(c) $a=0.005$

Fig. 10. Fracture propagation path of tuff stone cultural rock mass. 


\section{Conclusions}

Taking tuff stone monument as the research object, the mechanical mechanism of root splitting of stone monument was studied, and the main conclusions are as follows:

(1) There is a negative correlation between the root splitting expansion force and the crack morphology, and a positive correlation between the root splitting expansion force and the root growth expansion factor. There is a stress concentration phenomenon at the crack tip.

(2) The root splitting expansion force and tensile stress obtained by the equivalent thermal expansion method are in good agreement with the analytical solutions. The stress distribution of tuff stone monument under root splitting is central, the influence scope of root splitting on that is limited, and the tensile failure is mainly at the long axis.

(3) The fracture propagation of tuff stone monument rock mass extends along the long axis direction, there is a negative correlation between the length of the fracture and the length of the axial ratio of the elliptic fracture, and the fracture propagation path is different under different growth and expansion factors.

Though the variations of fracture deformation and propagation path obtained from the simulation results are consistent with the actual failure characteristics of the tuff stone monument, the other influencing factors such as physics and chemistry need to be considered in the next study.

\section{Acknowledgements}

This work was financially supported by the Basic Public welfare Research Project of Zhejiang Province (LGF20E080005).

This is an Open Access article distributed under the terms of the Creative Commons Attribution License.

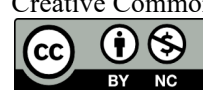

\section{References}

1. Yu, J. Q., Zhang, B. J., Shao, P. J., Feng, B. Y., "Survey on health assessment of grottoes and stone carvings in Zhejiang Province". Stone, (3), 2018, pp. 29-36.

2. Zhang, J. F., "Decay mechanism of stone monuments". Science of Conservation and Archaeology, 20(2), 2008, pp. 60-67.

3. Jiang, X. X., Wu, Q., Deng, X. L., Wang, X. L., Li, L. H., “Disease investigation of rock pillar cultural relics with complex shape and prevention measures-taking KeyanYungu rock pillar in Zhejiang Province as example". Geotechnical Investigation \& Surveying, 44(10), 2016, pp. 1-5.

4. Fan, W., Cheng, H. K., "Mechanism of plant root splitting in fractured rock mass". Science and Technology Innovation Herald, 12(35), 2015, pp. 46-47.

5. Malik, I., Pawlik, Ł., Ślęzak, A., Wistuba, M., "A study of the wood anatomy of Picea abies roots and their role in biomechanical weathering of rock cracks". Catena, 173, 2019, pp. 264-275.

6. Pawlik, Ł., Migoń, P., Owczarek, P., Kacprzak, A., "Surface processes and interactions with forestvegetation on a steep mudstone slope, Stołowe Mountains, SW Poland". Catena, 109, 2013, pp. 203-216.

7. Liu, T., Zhao, X. W., Liu, J. J., Wang, K., "Plant-induced diseases at an earthen site, using the Epang Palace Site as an example". Science of Conservation and Archaeology, 31(1), 2019, pp. $105-$ 110.

8. Zhang, K. X., Fu, X. Y., Chen, J. Q., Li, S. Y., "Geological research on protection of stone cultural relics: Feilaifeng Cliffside Sculptures". Bulletin of Science and Technology, 32(10), 2016, pp. 224-227.

9. Liu, S. L., Yang, B. G., Yao, J. F., Zheng, L., Zhang, P., Pang, S. J., Liao, S. S., Zou, W. X., "Study on stem radial growth of Castanopsis hystrix in Guangxi". Journal of South China Agricultural University, 41(5), 2020, pp. 82-90.

10. Calusi. B., Tramacere, F., Gualtieri, S., Pugno, N. M., Mazzolai, B., "Plant root penetration and growth as a mechanical inclusion problem". International Journal of Non-Linear Mechanics. 120, 2020, pp.12-16.

11. Kolb, E., Hartmann, C., Genet, P., "Radial force development during root growth measured by photoelasticity". Plant Soil, 360, 2012, pp. 19-35.

12. Su, W. J., Wang, J. H., Fu, M., Wu, R., "Formation mechanism and failure mode of perilous rocks in Bailiandong site". Coal Geology \& Exploration, 44(2), 2016, pp. 59-65.

13. Fulvio, Pi., Claudio, B., "Nonlinear micromechanical model for tuff stone masonry". Construction and Building Materials, 105(1), 2016, pp. 165-175.

14. Anthony, R., "Finite element models for rock fracture mechanics". Numerical and Analytical Methods in Geomechanics, 4(1), 1980, pp. 25-43.
15. Yun, T., Wang, X. P., Zhou, M., Miao, K., "Three-dimensional numerical study on the failure characteristics of intermittent fissures under compressive-shear loads". Acta Geotechnica, 14(4), 2019, pp: 1161-1193.

16. Kuksenko, V., Tomilin, N., "A two-stage model of fracture of rocks". Pure and Applied Geophysics, 146(3), 1996, pp. 253-263.

17. Niyaraki, M. M., Ghasemi, F. A., Ghasemi, I., Daneahpayeh, S. "Predicting of impact strength and elastic modulus of polypropylene/EPDM/graphene/glass fiber nanocomposites by response surface methodology". Technical Journal, 15(2), 2021, pp 169-177.

18. Ge, C., Ye, L., Wang, S. R., Jia, H. B., Li, S. T., Yang, J. H., Zhang, S., "Exploration method of stone statue based on nondestructive testing technology-taking Xinchang maitreya statue as an example". Journal of Engineering Science and Technology Review, 12(5), 2019, pp. 98-103.

19. Wang, S. R., Zhao, J. Q., Wu, X. G., Yang, J. H., Liu, A., "Meso-scale simulations of lightweight aggregate concrete under impact loading". International Journal of Simulation Modelling, 20(2), 2021, pp. 291-302.

20. Zhao, Y. H., Wang, S. R., Hagan, P., Guo, W. B., "Evolution characteristics of pressure-arch and elastic energy during shallow horizontal coal mining". Technical Gazette, 25(3), 2018, pp. 867-875.

21. Luo, P. P., Wang, S. R., Hagan, P., Huang, Q. X., Cao, C., Gamage, K., "Mechanical performances of cement-gypsum composite material containing a weak interlayer with different angles". Dyna, 94(4), 2019, pp. 447-454.

22. Miao, C. B., He, J., "Study of fracture mechanics in rock". Shanxi Architecture, 40(3), 2014, pp. 83-85.

23. Cui, H. B., Wang, C. J., "Calculating method for stress of gravity dam based on elasticity theory". Journal of Zhongzhou University, 9(3), 2012, pp. 118-122.

24. Belytschko, T., Black, T., "Elastic crack growth in finite eleme-nts with minimal remeshing". International Journal for Numerical Methods in Engineering, 45(5), 1999, pp. 601-620.

25. Xiao, J. H., Xu, Y. L., Zhang, F. C., "Fracture mechanics of a cracked elliptical hole based on the surface elasticity theory", Chinese Journal of Solid Mechanics, 40(1), 2019, pp. 82-89.

26. Xu, F., Wang, M., "Weathering degree analysis of cliff statues in Nanshan, Zhejiang". Stone, (11), 2014, pp. 39-43.

27. Shi, W. B., "The relationship between diameter growth and spatial structure of larch plantation in mountain area of northern Hebei Province". The Journal of Hebei Forestry Science and Technology, (1), 2021, pp. 11-14. 